\title{
In situ Derived Electrocatalysts from Fe-Co Sulfides with Enhanced Activity towards Oxygen Evolution
}

Yuanjun Liu, ${ }^{*}{ }^{\dagger}$ Suxiao Ju, ${ }^{\dagger}$ Cheng Wang, ${ }^{\dagger}$ Mo Li, ${ }^{\dagger}$ Wenjuan Zhu, ${ }^{\ddagger}$ Danyang Chen, ${ }^{\dagger}$

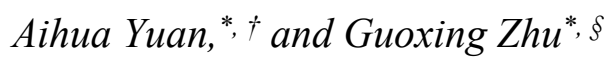

'School of Environmental and Chemical Engineering, Jiangsu University of Science and Technology, Zhenjiang 202018, China, *Email: liuyuanjun@just.edu.cn;

aihua.yuan@just.edu.cn

\#School of Chemistry and Chemical Engineering, Hefei Normal University, Hefei

$$
\text { 230601, China }
$$

\$School of Chemistry and Chemical Engineering, Jiangsu University, Zhenjiang 212013, China, *E-mail: zhuguoxing@ujs.edu.cn 


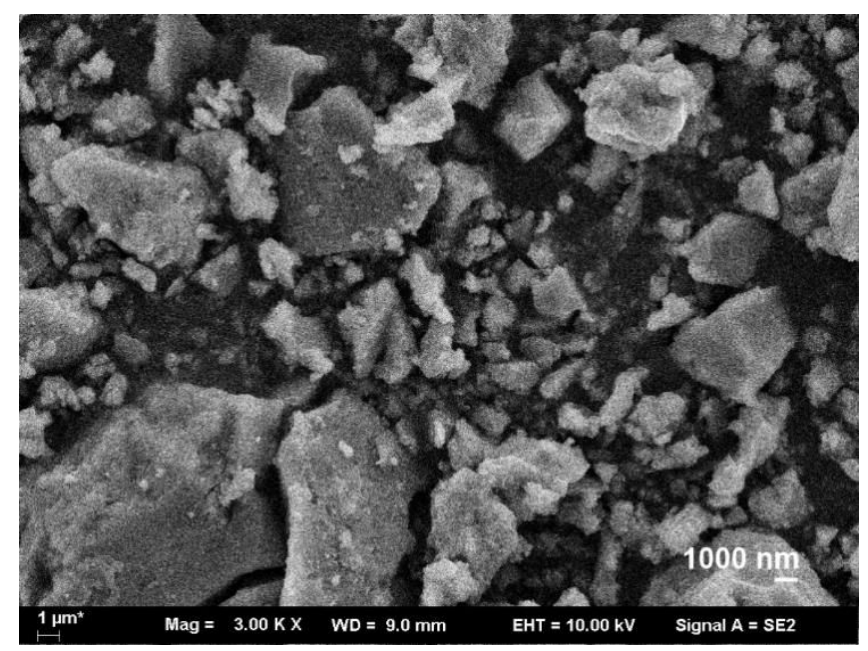

Figure S1. SEM image of the FeCo-S-150 product.
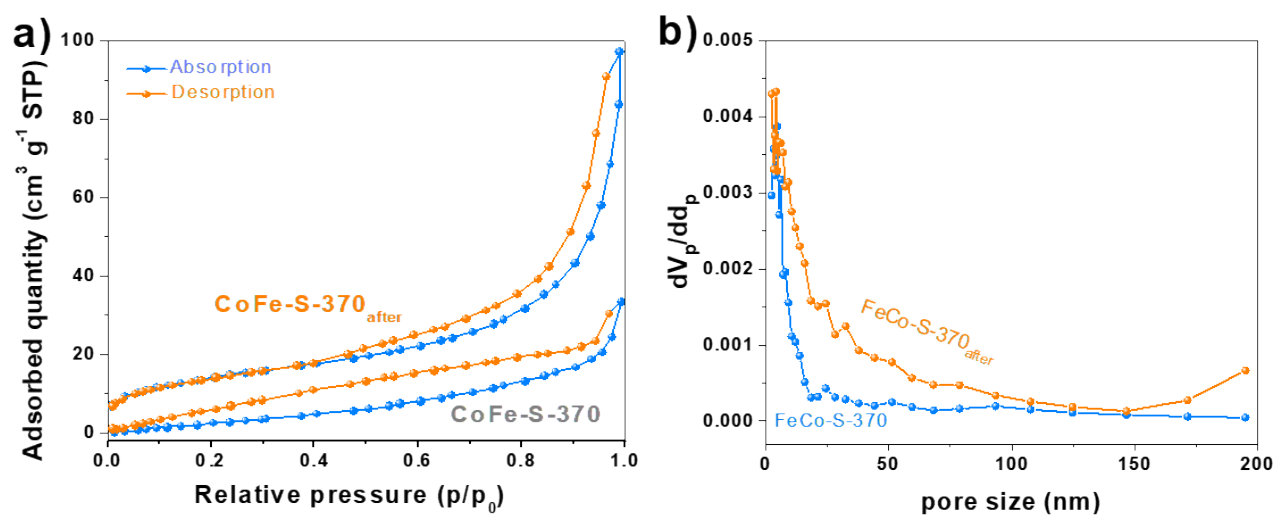

Figure S2. a) Typical $\mathrm{N}_{2}$ adsorption-desorption curves of the FeCo-S-370 and FeCo-S-370 $0_{\text {after }}$ products. b) The corresponding pore size distribution obtained from the adsorption branch of the isotherms by the BJH method. 

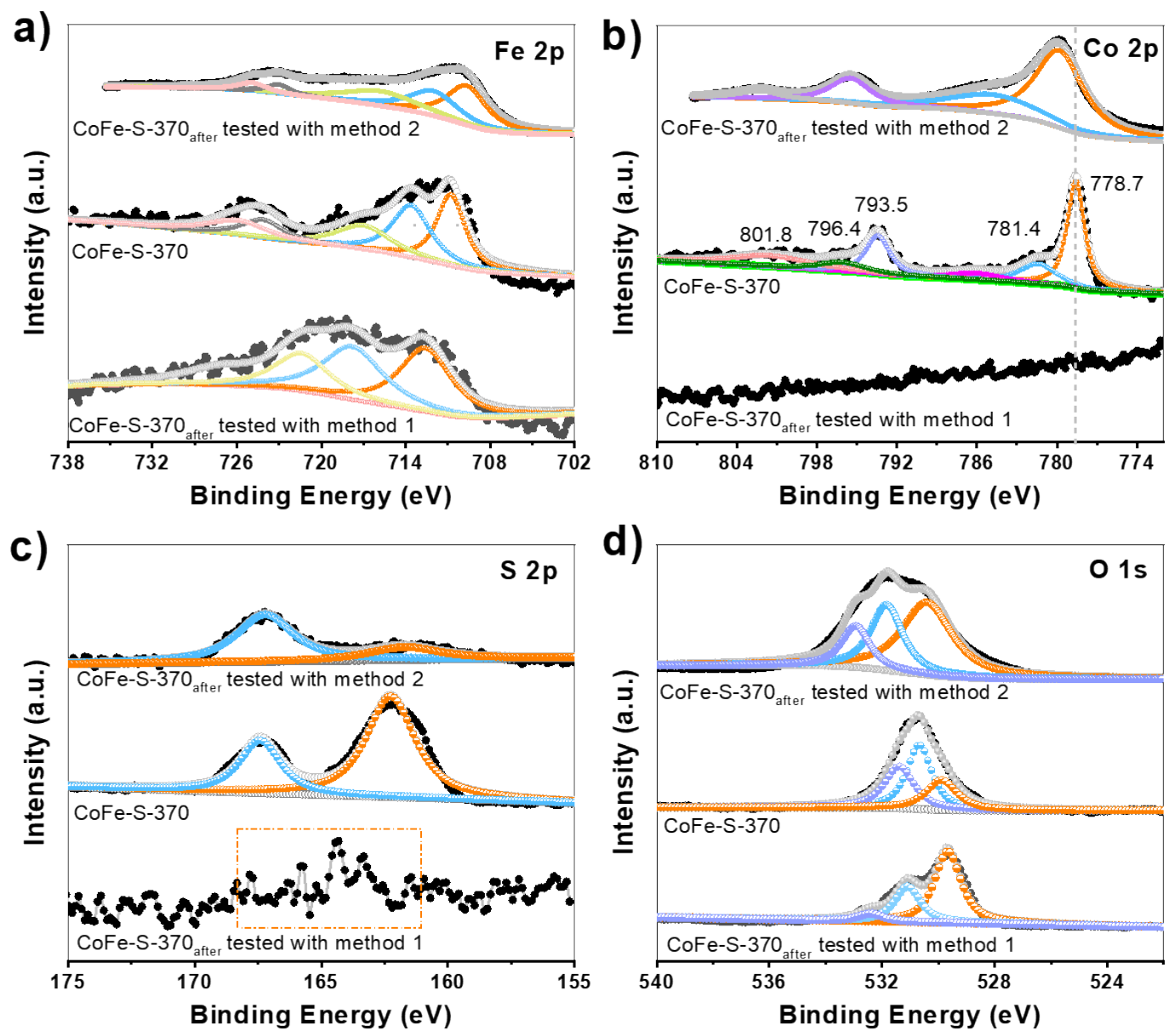

Figure S3. XPS spectra of FeCo-S-370 and FeCo-S-370 after products tested with two different methods. Method 1: XPS investigation is directly measured on the metal foam electrode, which can show the actual information of catalyst layer surface after OER. Method 2: XPS measurement is conducted on the powder sample that scratched from the electrode after OER. The thus obtained XPS spectra show the comprehensive information of catalyst layer surface and catalyst layer interior after OER. a) Co 2 p region, b) Fe $2 p$ region, c) S 2 p region, and d) O 1 s region. 

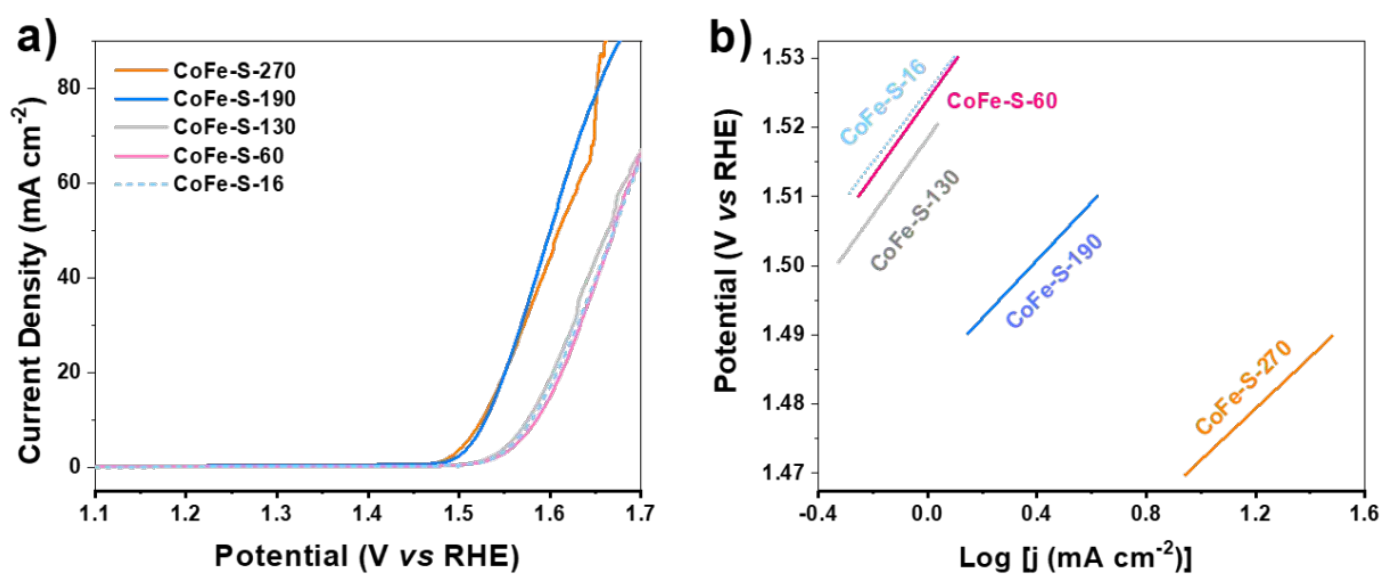

Figure S4. a) LSV curves of the synthesized iron-cobalt sulfide products prepared with different sulfur dosage (CoFe-S-190, CoFe-S-130, CoFe-S-60, CoFe-S-16) in $1 \mathrm{M} \mathrm{KOH}$ aqueous solution at scanning rate of $5 \mathrm{mV} \mathrm{s}^{-1}$. b) The corresponding Tafel plots derived from the LSV curves.
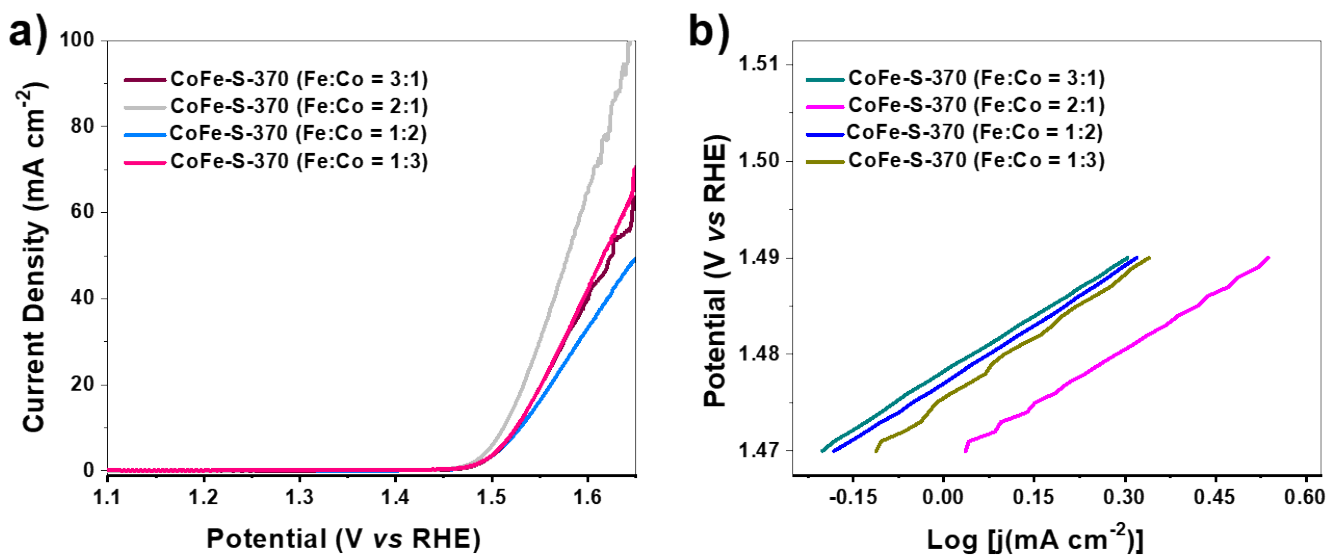

Figure S5. a) LSV curves of the synthesized iron-cobalt sulfide products with different $\mathrm{Fe}: \mathrm{Co}$ molar ratios in $1 \mathrm{M} \mathrm{KOH}$ aqueous solution at scanning rate of 5 $\left.\mathrm{mV} \mathrm{s}^{-1} . \mathrm{b}\right)$ The corresponding Tafel plots derived from the LSV curves. 

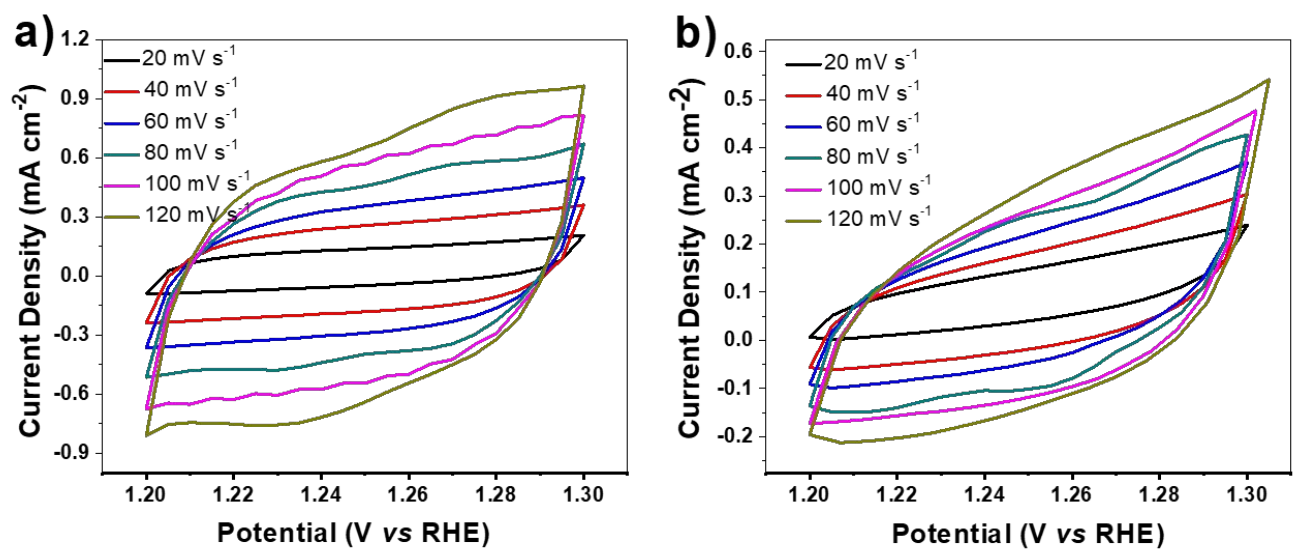

Figure S6. Cyclic voltammetry curves of a) FeCo-S-150 and b) FeCo-S-370 products.
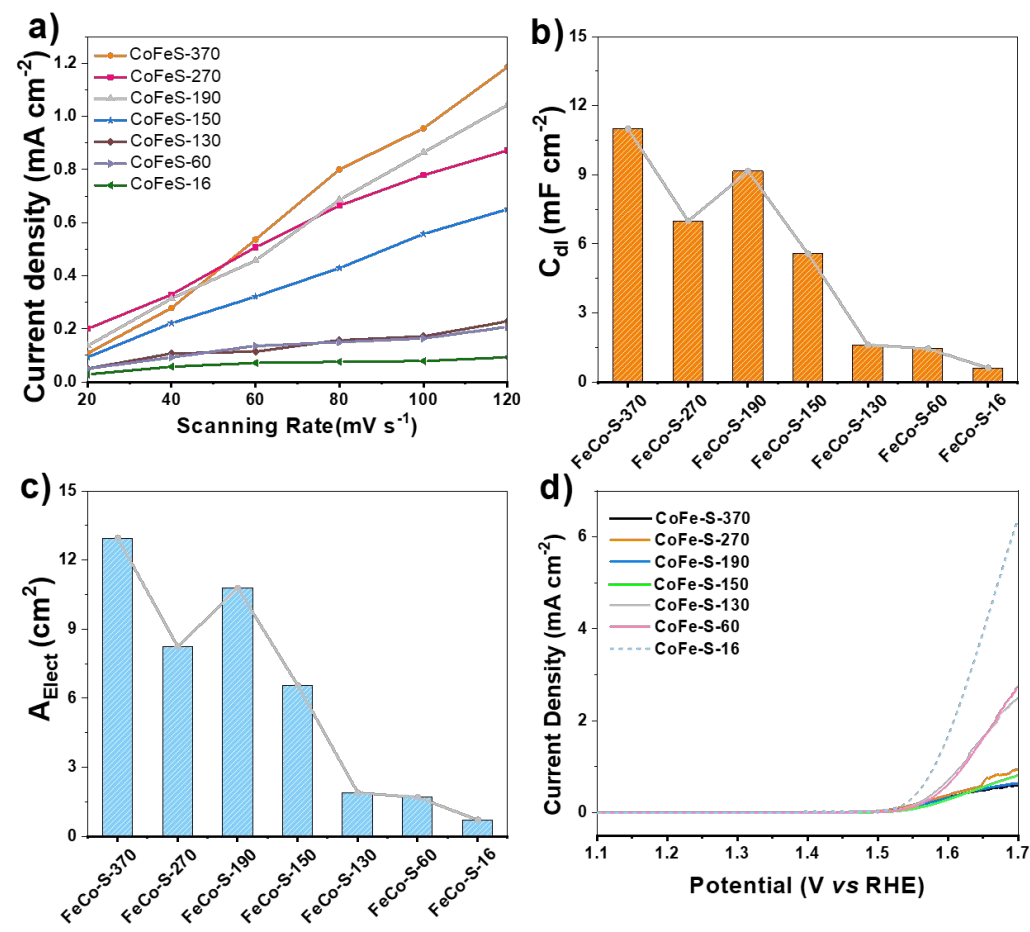

Figure S7. a) Double layer capacitance $\left(\mathrm{C}_{\mathrm{dl}}\right)$ values obtained by plotting of the current density, $\left(\mathrm{j}_{\mathrm{a}}-\mathrm{j}_{\mathrm{c}}\right) / 2$, vs scanning rate. b) Comparison of the $\mathrm{C}_{\mathrm{dl}}$ values, c) the electrochemically active specific surface area of the catalyst loaded electrode $\left(\mathrm{A}_{\text {Elect }}\right)$ calculated from $\mathrm{C}_{\mathrm{dl}}$ values based on the following equation,

$$
A_{\text {Elect }}=A_{\text {Geom }} \times \frac{C_{d l}}{C_{d l-\text { ref }}}
$$

where $\mathrm{C}_{\mathrm{dl}}$ value of a flat electrode is $60 \mu \mathrm{F} \mathrm{cm}{ }^{-2}\left(\mathrm{C}_{\mathrm{dl}-\mathrm{Ref}}\right),{ }^{1-2} \mathrm{~A}_{\mathrm{Geom}}$ is $0.0707 \mathrm{~cm}^{2}$ for our electrode. d) LSV curves of various samples normalized by $\mathrm{A}_{\text {Elect }}$. 
Table S1. The composition of the obtained cobalt-iron sulfide products analysed by ICP.

\begin{tabular}{lcc}
\hline Samples & $\begin{array}{c}\text { Fe content analyzed } \\
\text { by ICP }(\text { wt } \%)\end{array}$ & $\begin{array}{c}\text { Co content analyzed } \\
\text { by ICP (wt \%) }\end{array}$ \\
\hline FeCo-S-370 & 11.3 & 11.7 \\
FeCo-S-370 after 34 h of OER & 23.5 & 21.8 \\
\hline
\end{tabular}

Table S2. Fitted results of the Nyquist plots for the products of FeCo-S-370, FeCo-S-150, $\mathrm{Fe}_{3} \mathrm{Co}-\mathrm{S}-370$, and d) $\mathrm{FeCO}_{3}-\mathrm{S}-370$.

\begin{tabular}{lccc}
\hline Samples & $\mathrm{R}_{\mathrm{s}}(\mathrm{ohm})$ & $\mathrm{R}_{\mathrm{ct}}(\mathrm{ohm})$ & $\mathrm{C}_{1}(\mathrm{~F})$ \\
\hline FeCo-S-370 & 10.7 & 19.5 & $2.5 \times 10^{-4}$ \\
$\mathrm{FeCo}-\mathrm{S}-150$ & 12.4 & 35.8 & $5.0 \times 10^{-4}$ \\
$\mathrm{Fe}_{3} \mathrm{Co}-\mathrm{S}-370$ & 11.3 & 42.4 & $5.0 \times 10^{-5}$ \\
$\mathrm{FeCo}_{3}-\mathrm{S}-370$ & 26.6 & 28.3 & $1.7 \times 10^{-4}$ \\
\hline
\end{tabular}

\section{References:}

(1) Cui, B.; Lin, H.; Li, J.-B.; Li, X.; Yang, J.; Tao, J. Core-ring structured $\mathrm{NiCo}_{2} \mathrm{O}_{4}$ nanoplatelets: synthesis, characterization, and electrocatalytic applications. $A d v$. Funct. Mater. 2008, 18, 1440.

(2) Jiang, H.; He, Q.; Li, X.; Su, X.; Zhang, Y.; Chen, S.; Zhang, S.; Zhang, G.; Jiang, J.; Luo, Y.; Ajayan, P. M.; Song, L. Tracking structural self-reconstruction and identifying true active sites toward cobalt oxychloride precatalyst of oxygen evolution reaction. Adv. Mater. 2019, 31, 1805127. 